\title{
Síndrome da Hiperestesia Felina - Relato de Caso
}

\author{
Feline Hyperesthesia Syndrome - Case Report
}

\section{Danilo Barbosa Viana ${ }^{1}$, Adilson Paulo Marchioni Cabral ${ }^{2}$, Ana Paula Lourenção Albuquerque ${ }^{3}$, Felipe Jacques Sanches ${ }^{4}$, Marilda Onghero Taffarel ${ }^{3}$, Paulo Fernandes Marcusso ${ }^{5 *}$}

${ }^{1}$ Universidade Estadual de Londrina, Londrina, Paraná, Brasil.

Universidade Estadual Paulista "Júlio de Mesquita Filho", Jaboticabal, São Paulo, Brasil.

${ }^{3}$ Universidade Estadual de Maringá, Umuarama, Paraná, Brasil.

"Universidade Estadual Paulista "Júlio de Mesquita Filho", Botucatu, São Paulo, Brasil.

${ }^{5}$ Universidade Federal dos Vales do Jequitinhonha e Mucuri, Unaí, MG, Brasil. *Autor para correspondência: paulomarcusso@gmail.com

Submissão: 12/04/2019 / Aceite: 22/06/2020

\begin{abstract}
RESUMO
A Síndrome da Hiperestesia Felina (FHS) é uma condição clínica, caracterizada por contrações musculares involuntárias e mudanças de comportamento. É uma síndrome rara, muitas vezes de origem desconhecida, sendo que as causas mais comuns associadas são doenças relacionadas à pele, tais como dermatites bacterianas, fúngicas, alérgicas e doenças imunomediadas. Causas relacionadas ao sistema nervoso central e distúrbios comportamentais também são relatadas. Os sinais clínicos são variados, o diagnóstico muitas vezes é complexo e o tratamento varia de acordo com a causa de base. $O$ objetivo deste relato de caso é descrever um caso de FHS de possível origem dermatológica. Um felino, macho, de três anos, da raça Siamês, foi atendido apresentando doença do trato urinário inferior felino há nove dias. Associado, o animal possuía áreas eritematosas e de hipotricose por toda a face, principalmente ao redor dos olhos, nariz e pavilhões auriculares, juntamente com hipersensibilidade dolorosa ao toque e fasciculações cutâneas na região lombar, coccígea e membros pélvicos. Foi realizado exame histopatológico das lesões de pele, onde foi visualizada dermatite superficial perivascular crônica proliferativa. Com base nos achados de exame físico e nos exames complementares, o animal foi diagnosticado com síndrome da hiperestesia felina secundária à dermatopatia.
\end{abstract}

PALAVRAS-CHAVE: distúrbio comportamental, neurologia, pênfigo.

\begin{abstract}
Feline Hyperesthesia Syndrome (FHS) is a clinical condition, characterized by involuntary muscle contractions and changes in behavior. It is a rare syndrome, often of unknown origin, and the most common associated causes are skin related disorders, such as bacterial, fungal dermatitis, allergics and immune-mediated diseases. Causes related to the central nervous system and behavioral disorders are also reported. The clinical signs are varied, the diagnosis is often complex and the treatment varies according to the underlying cause. The purpose of this case report is to describe a case of FHS of possible dermatological etiology. A three-year-old Siamese male feline was treated for feline lower urinary tract disease throughout the duration of nine days. Associated, the animal also presented erythematous areas and hypotrichosis all over the face, especially around the eyes, nose and auricular pavilions, along with painful hypersensitivity to the touch and skin fasciculations in the lumbar and coccygeal region and pelvic limbs. An histopathological exam of the skin lesions was performed, where a chronic, superficial perivascular dermatitis was seen to be proliferative. Based on physical examination findings and additional tests, the animal was diagnosed with feline hyperesthesia syndrome secondary to dermatopathy.
\end{abstract}

KEYWORDS: behavioral disorder, neurology, pemphigus.

A Síndrome da Hiperestesia Felina (FHS) caracteriza-se por um conjunto de manifestações clínicas, muitas vezes de início súbito e inesperado, onde o animal pode apresentar contrações musculares involuntárias e alterações de comportamento (MOLINER \& STEVERS 2013, MANDIGERS \& BERGKNUT 2016). É conhecida também como neurodermatite, neurite, epilepsia psicomotora, dermatite pruriginosa do Siamês e pelos termos em inglês "rolling skin disease" ou "rippling skin disease", devido a um dos principais 
sinais clínicos da doença, que é a contração dos músculos da região dorsal do animal (MOLINER \& STEVERS 2013).

Pode ocorrer em gatos de todas as idades, no entanto, é mais observada em animais entre um a cinco anos de idade. Não há predileção por sexo e todas as raças podem ser afetadas, entretanto, os gatos siameses, birmaneses, persas e abissínios parecem ser os mais acometidos (CIRIBASSI 2009).

É uma afecção multifatorial e várias possíveis causas estão envolvidas. As mais frequentes são problemas neurológicos, dermatológicos e desvios comportamentais (CARDÓs 2016). Em relação às causas neurológicas, as mais prováveis são movimentos paroxísticos com fasciculações e distúrbios de comportamento causados por uma hiperinervação dopaminérgica anormal em resposta a um estímulo inflamatório local, crises epiléticas focais, mielopatias e neuropatias sensitivas, além de tumores cerebrais e medulares (MANDIGERS \& BERGKNUT 2016).

As causas dermatológicas mais comuns são aquelas relacionadas a um estímulo inflamatório cutâneo e hipersensibilidades, como dermatite alérgica a picada/saliva da pulga, infecções bacterianas e fúngicas, ácaros, hipersensibilidade alimentar, doenças imunomediadas e atopia que levam a dor e irritação local (LANDSBERG et al. 2013).

O diagnóstico baseia-se no histórico do paciente (anamnese detalhada) e exame físico completo, para que se diminua o leque de diagnósticos diferenciais. Exame ortopédico e neurológico também são indicados, embora animais com hiperestesia felina normalmente não possuam alterações no exame neurológico, salvo quando a causa é relacionada a este sistema. Exames complementares como hemograma, bioquímicos e sorologias para doenças infecciosas costumam estar sem alterações (DEWEY \& DA COSTA 2017).

Pode ser realizada ainda mensuração dos hormônios tireoidianos para descartar hipo/hipertireoidismo, além de exames de imagem, como tomografia e ressonância magnética para descartar lesões em sistema nervoso central. Caso o animal possua lesões cutâneas, é indicado um raspado da região afetada em busca de ácaros e biópsia das lesões em busca de doenças autoimunes (CARDÓs 2016).

O tratamento para essa doença baseia-se na sua causa de base. Segundo MOLINER \& STEVERS (2013), a maioria dos animais responde ao tratamento com fármacos acaricidas, controle de ectoparasitos e mudanças de dieta, como a implementação de ração hipoalergênica. Tudo isso pensando em uma causa alérgica ou nas hipersensibilidades.

Considerando a importância de descobrir a causa base da doença, que muitas vezes é subdiagnosticada na rotina clínica, visto que seu diagnóstico é realizado por exclusão de diversos fatores, esse trabalho tem como objetivo relatar um caso de FHS de provável etiologia dermatológica.

Deu entrada no Hospital Veterinário da Universidade Estadual de Maringá, no dia 18 de agosto de 2017 um felino, macho, não castrado, de três anos de idade, da raça siamês apresentando oligúria, disúria, polidipsia, aumento de volume abdominal com dor a palpação e hiporexia há sete dias. Há 25 dias o animal foi levado à outro médico veterinário com a queixa de anúria, dificuldade de locomoção e vocalização excessiva, sendo diagnosticado com cistite. Foi recomendado a ida na clínica veterinária durante nove dias consecutivos para administração de medicamentos, no entanto o proprietário não soube informar quais eram as medicações nem a frequência de aplicação e relatou que logo após o final do tratamento animal voltou a apresentar disúria. Há 15 dias, proprietário também notou presença de lesões alopécicas, eritematosas, com crostas e não pruriginosas na região de plano nasal, periocular, superfícies interna e externa de ambos os pavilhões auriculares. Não foi referido em nenhum momento pelo proprietário hipersensibilidade dolorosa em alguma região do corpo do animal.

Ao exame físico foi constatado animal deprimido, com escore de condição corporal 3/9 e com dor a palpação abdominal e lombar. Havia presença de áreas de hipotricose e eritematosas por toda a face e pavilhões auriculares (Figura 1). $\mathrm{O}$ animal possuía hipersensibilidade dolorosa e fasciculações cutâneas principalmente de região lombar, coccígea e membros pélvicos. Foi realizada massagem peniana e, durante o procedimento, foi expelido um tampão uretral.

Foram realizados, no dia da consulta do animal, exames complementares, como hemograma, exames bioquímicos, urinálise e cultura microbiológica da urina, coproparasitológico, ultrassom abdominal, além de exame histopatológico das lesões cutâneas na face. No hemograma foi possível observar leucocitose por neutrofilia sem desvio (número de leucócitos totais: $23.400 / \mu \mathrm{L}$ e número de neutrófilos segmentados: $20.358 / \mu \mathrm{L}$ ). Nos exames bioquímicos, os valores de creatinina, fosfatase alcalina e alanina aminotransferase encontravam-se dentro dos valores de referência da espécie, enquanto que a ureia $(47,7$ $\mathrm{mg} / \mathrm{dL})$ e proteínas totais $(9 \mathrm{~g} / \mathrm{dL})$ mostraram-se acima dos valores de referência. Foi realizada também 
coleta de urina por cistocentese para realização da urinálise, na qual foi visto urina de coloração amarelo ouro, odor inodoro, aspecto levemente turvo, densidade acima de 1,040, proteinúria $(++)$, leucocitúria (10 leucócitos por campo), hematúria (10 hemácias por campo), bacteriúria $(++)$, além da presença de espermatozoides. Na cultura microbiológica, foram isoladas bactérias do gênero Staphylococcus spp. No exame coproparasitológico, realizado pelos métodos de Willis e Faust, foi visualizado o parasito Ancylostoma spp. Ao exame ultrassonográfico foi visualizado imagem sugestiva de glomerulonefrite/nefrite intersticial bilateral e cistite com presença de micro cálculos vesicais, além de esplenomegalia. No raspado cutâneo das lesões na região da face e orelhas não foi visualizado presença de ácaros ou fungos.

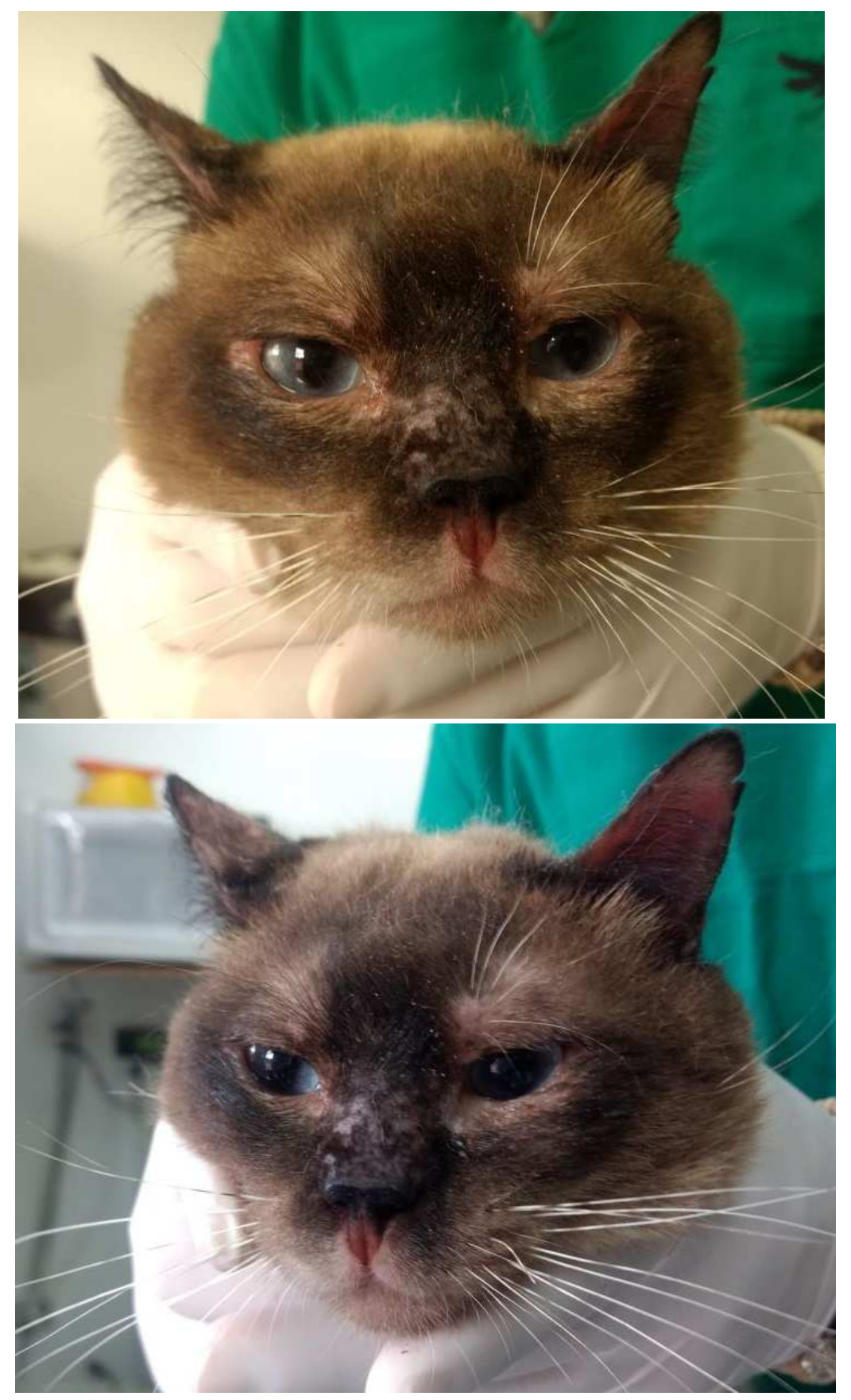

Figura 1. Fotografias do aspecto macroscópico das alterações cutâneas. Presença de áreas de hipotricose, eritematosas e com presença de crostas em região de plano nasal, periocular e em superfície interna e externa do pavilhão auricular.

Figure 1. Photographs of the macroscopic aspect of skin changes. Presence of areas of hypotrichosis, erythematous and presence of crusts in the region of the nasal plane, periocular and on the inner and outer surface of the pinna.

Das lesões de pele presentes no plano nasal foram retirados três pequenos fragmentos cutâneos, medindo $8 \times 3 \times 3 \mathrm{~mm}$ e $7 \times 1 \times 1 \mathrm{~mm}$, para realização do exame histopatológico, no qual foi visualizado 
dermatite superficial perivascular crônica proliferativa, com epiderme apresentando hiperplasia regular e ortoqueratose leve, além de infiltrado inflamatório misto principalmente na derme.

O paciente ficou internado durante quatro dias no hospital veterinário. No segundo dia de internamento a hipersensibilidade se intensificou de forma súbita, abrangendo também região sacral, base da calda e membros, que se estendeu até o dia da alta do paciente, caracterizando FHS. Durante os dias de internamento, o paciente foi tratado com Dipirona $25 \mathrm{mg} / \mathrm{Kg} / \mathrm{SID}$, Metadona 0,3 mg/Kg, Acepromazina $0,03 \mathrm{mg} / \mathrm{Kg} / \mathrm{SID}$ e Meloxicam 0,1 mg/Kg/SID. O paciente recebeu alta dia 22 de agosto de 2017, sendo prescrito para casa Amitriptilina (1,64 mg/Kg/BID durante $30 \mathrm{dias})$, Meloxicam $(0,03 \mathrm{mg} / \mathrm{Kg}$ a cada $48 \mathrm{~h}$ durante $10 \mathrm{dias}$ ), dipirona (25 mg/Kg/SID durante $10 \mathrm{dias})$, codeína ( $1 \mathrm{mg} / \mathrm{Kg} / \mathrm{BID}$ durante 10 dias), amoxicilina com clavulonato (20 mg/Kg/BID durante 10 dias), suplemento alimentar a base de Condroitina, Glicosamina, Extrato de Yucca e Minerais (1/2 comprimido/SID durante 30 dias), vermífugo a base de Praziquantel, Febantel e Pirantel (1 comprimido/SID em dose única) e Selamectina 6\% para gatos de 2,5 a $7,5 \mathrm{~kg}$.

A FHS é corriqueiramente associada a um transtorno compulsivo que resulta em um comportamento autodestrutivo do animal. O desenvolvimento desse transtorno é associado a causas ambientais que geram estresse, excitação, conflito, frustração e ansiedade. Esses fatores influenciam estimulando o hipotálamo e o sistema límbico que, por sua vez, ativam a atividade motora através dos gânglios basais, o que leva aos sinais clínicos característicos (CIRIBASSI 2009).

Como descrito acima, o fator estresse pode ser uma das causas etiológicas do desencadeamento da síndrome. No caso em questão, o animal vinha apresentando sinais clínicos intermitentes relacionados a uma possível doença do trato urinário inferior felino há quase um mês. As idas diárias ao médico veterinário, associado à administração de medicamentos injetáveis e a dor devido à cistite bacteriana instalada podem ter levado o animal a um estado de estresse, que culminou com o aparecimento dos sinais clínicos característicos da FHS.

A síndrome caracteriza-se por crises episódicas, que ocorrem mais pela manhã ou no começo da noite e podem ser induzidos pelo simples fato de tocar ou acariciar a região lombar do animal. Os principais sinais clínicos apresentados pelos animais acometidos são ondulações e fasciculações da pele sobre o dorso, principalmente região lombar e espasmos musculares na região epaxial toracolombar (CIRIBASSI 2009, DEWEY \& DA COSTA 2017), que ocorrem de forma súbita e inesperada (MANDIGERS \& BERGKNUT 2016). No presente caso o animal apresentava-se incomodado e tentava fugir ao ser tocado em região lombar, coccígea e membros pélvicos junto com fasciculações da pele nessas regiões.

Os animais também podem apresentar lambeduras e mordiscamentos excessivos nessas áreas, chegando a formar lesões e feridas, vocalização excessiva, midríase, corrida frenética e sem rumo, chegando a defecar enquanto correm, movimento exagerado da cauda, ataque a objetos inanimados e pessoas, alucinações e mudanças de comportamento (LANDSBERG et al. 2013, DEWEY \& DA COSTA 2017). Durante a anamnese o proprietário não referiu nenhum desses comportamentos ou ações, no entanto, durante o exame físico, o animal apresentou comportamento agressivo, tentando atacar o examinador e fugir quando era simplesmente tocado na região lombar, coccígea e nos membros pélvicos.

Causas de origem cutânea também estão associadas à etiologia da FHS, principalmente estímulos inflamatórios e hipersensibilidades, como dermatite alérgica a picada/saliva da pulga, infecções bacterianas e fúngicas, ácaros, hipersensibilidade alimentar, doenças imunomediadas e atopia que levam a dor e irritação local (LANDSBERG et al. 2013). No relato aqui exposto o animal apresentava áreas de alopecia, eritema e crostas por toda a face e pavilhões auriculares. Devido a esses sinais clínicos levantou-se a suspeita de pênfigo foliáceo, visto que, segundo MEDLEAU \& HNILICA (2003), animais com essa doença apresentam erosões superficiais, crostas, descamação e alopecia que se iniciam no nariz, ao redor dos olhos e no pavilhão auricular.

Segundo MEDLEAU \& HNILICA (2003), as características vistas ao exame histopatológico do pênfigo foliáceo são principalmente pústulas subcorneais e células acantolíticas. Amostras foram coletadas das lesões do animal do presente caso, onde o exame histopatológico evidenciou áreas de dermatite superficial perivascular crônica proliferativa, sendo, portanto, um achado inespecífico, não caracterizando pênfigo foliáceo. Segundo WERNER (2002), os achados histopatológicos vistos no caso poderiam ser compatíveis com outras doenças, como pênfigo eritematoso, dermatite por Malassezia spp. e linfoma epiteliotrópico.

Outro possível diagnóstico diferencial seria dermatite alérgica a saliva/picada de pulgas, visto que a proprietária não fazia o controle periódico e relatou presença desses ectoparasitos, que também foram visualizados durante o exame físico. Outro fato que sustenta a hipótese é o processo inflamatório inespecífico visto no exame histopatológico, que poderia estar sendo induzido pela reação de 
hipersensibilidade. Entretanto, segundo LITTLE (2015), a dermatite alérgica a pulgas caracteriza-se principalmente por áreas de alopecia, descamação e erupções papulares crostosas ou não com intenso prurido nas regiões lombossacra, membros posteriores e pescoço. Durante a anamnese o tutor não relatou prurido ou lesões nessas áreas, que também não foram visualizadas durante o exame físico.

Segundo a Food and Drug Administration (FDA), agência federal de regulação de medicamentos dos Estados Unidos, não existe nenhum fármaco aprovado para o tratamento da FHS ou de qualquer outro transtorno compulsivo em animais. Por esse motivo, é essencial deixar claro ao proprietário os potenciais efeitos colaterais e benefícios do uso farmacológico, lembrando que são essenciais os testes bioquímicos de função hepática e renal antes do inicio do tratamento e mensalmente durante a administração das drogas, para verificar possível toxicidade em ambos os órgãos (CIRIBASSI 2009). No presente caso o proprietário foi informado de todos os riscos e exames que deveriam ser realizados antes e durante 0 tratamento, aceitando fazê-los.

Os fármacos mais utilizados para o tratamento são os inibidores seletivos da recaptação da serotonina (ISRS), os antidepressivos tricíclicos e os benzodiazepínicos (CARDÓS 2016).

Foi receitado o uso de amitriptilina $(1,64 \mathrm{mg} / \mathrm{Kg} / \mathrm{BID}$ durante 30 dias) para melhora da síndrome compulsiva. A amitriptilina foi escolhida por ser um antidepressivo tricíclico e que tem como mecanismo de ação a inibição da recaptação da serotonina-norepinefrina, pois uma vez aumentado os níveis de serotonina, espera-se redução da incidência de transtornos compulsivos. Houve melhora dos sinais clínicos nos primeiros dias de tratamento, porém, 15 dias depois proprietário passou a não fazer o tratamento adequadamente, não retornando para as reavaliações e o hospital não conseguiu mais contanto com o mesmo. Dessa forma não tendo resultados sobre a resposta do animal frente ao tratamento.

O'LEARY (2015) relatou o tratamento somente com acupuntura de um gato com FHS secundária a amputação do membro pélvico direito. $O$ animal passou por quatro sessões de acupuntura semanalmente, depois uma sessão a cada 21 dias, voltando ao comportamento normal. Contudo não foi realizada a acupuntura no presente relato.

Por meio da anamnese, exame físico e exames complementares foi possível identificar que o animal apresentou a Síndrome da Hiperestesia Felina (FHS), contudo não foi possível identificar a causa base para o desenvolvimeto dela, que pode estar associada à dermatopatia, ao estresse provocado pela doença do trato urinário, bem como à somatória dessas doenças, haja vista que ambas podem contribuir para 0 desenvolvimento da FHS.

\section{REFERÊNCIAS}

CARDÓS SL 2016. Hiperestesia felina Madrid: AEVA. Disponível em: <https://aevaveterinaria.es/index.php/component/k2/25-hiperestesia-felina>. Acesso em: 28 fev. 2018.

CIRIBASSI J 2009. Understanding behavior: feline hyperesyhesia síndrome. Compendium Continuing Education for Veterinarians 31: 116-132.

DEWEY CW \& DA COSTA RC 2017. Neurologia canina e felina - guia prático. 1.ed. São Paulo: Editora Guará. 752p.

LANDSBERG GM et al. 2013. Behavior Problems of the Dog and Cat. 3.ed. London: Elsevier. 472p.

LITTLE SE. 2015. O Gato: Medicina Interna. 1.ed. Rio de Janeiro: Roca. 1332p.

MANDIGERS PJJ \& BERGKNUT N. 2016. Feline hyperesthesie syndroom. Tijdschrift voor Diergeneeskunde 3: 2-3.

MEDLEAU L \& HNILICA KA. 2003. Dermatologia de pequenos animais: atlas colorido e guia terapêutico. 1.ed. São Paulo: Roca. 353p.

MOLINER CM \& STEVERS PM. 2013. Síndrome da Hiperestesia Felina. Boletim de Etologia 12: 5-6.

O'LEARY DJ. 2015. Swallowed needle in a cat treated for feline hyperaesthesia syndrome. Acupuncture in Medicine 33 : 336-337.

WERNER J. 2002. Avaliação histopatológica das dermatopatias de pequenos animais diagnosticadas entre janeiro de 1998 e abril de 2001 em Curitiba - Paraná. Dissertação (Mestrado em Ciências Veterinárias). Curitiba: UFPR. 64p. 